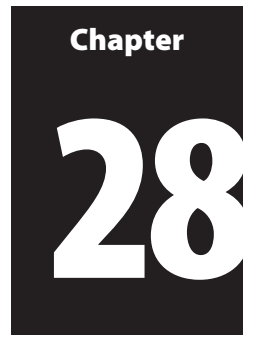

\title{
The Origins of the Dangerous and Severe Personality Disorder Programme in England
}

\author{
Peter Tyrer
}

It is lack of appreciation and understanding of this factor (psychopathic personality) which has often led to a great deal of prolonged, useless, faulty and even dangerous treatment.

David Henderson, $1951^{1}$

\section{Introduction}

The Dangerous and Severe Personality Disorder (usually abbreviated to DSPD) richly funded 'treatment' programme was introduced in the late 1990s by the then Labour government. It attempted to combine psychiatric diagnosis and treatment for severe personality disorder, but its main aim was public protection. Unsuccessful attempts were made to enshrine the 'treatment' programme in law. They met widespread resistance on human rights grounds by psychiatrists and other mental health professionals as well as service user-led organisations and all failed.

The exact origin of the concept of the DSPD programme remains an enigma. I will try to piece together the strands, focusing mainly on political actors, while appreciating that some will be left hanging in the air. What I hope to elucidate is that initiatives taken by government without the profession approving are rarely likely to succeed.

In this account, I am appreciative of all the contributions made by those listed in the Acknowledgements section of this chapter and also of the very detailed and scholarly account in Max Rutherford's Blurring the Boundaries, published by the Sainsbury Centre in 2010. This is one of a few documents published about the programme that can be regarded as completely unbiased. Most of the other published papers, including many from government sources, are tendentious and misleading. Although I would like to exclude our own published papers on the subject, ${ }^{2}$ I feel even they, despite attempts to be neutral, have a tendency to overstate in their attempt to correct errors on the other side.

\section{Early History}

The story appears to start on 9 July 1996. Lin Russell, a mother aged forty-five, was walking home with her two daughters, Josie, aged nine, and Megan, aged six, and their dog down a quiet country lane near Canterbury in Kent after a school swimming competition.

Out of the blue, they were attacked. A man tied them up, blindfolded them and then beat them all indiscriminately. They all died apart from Josie, who after a rocky rehabilitation, has, gratifyingly, almost completely recovered.

The case was difficult to resolve, but in July 1997, Michael Stone, a heroin addict at that time on probation, was arrested and charged with murder. There is still great doubt that he 
was the murderer and Levi Bellfield, the man convicted of the murder of Milly Dowler in March 2002, has also been accused of the crimes.

The shocking case of Lin Russell and her family is said to be the stimulus behind the DSPD programme. Why was it that a man who was recognised to be unwell, with diagnosed antisocial or psychopathic disorder, was allowed to be at liberty and yet remain a big risk to the public. Psychiatrists regarded these people as untreatable, but were they right and what could be done to prevent it?

In all my enquiries, there has been one consistent feature in the timeline. It was the attack on the Russell family, followed by the widespread public reaction, that initiated the implementation of the DSPD programme.

\section{Political Action between 1997 and 1999}

In Chapter 9, I report on an interview with the former Conservative secretary for health and social services, Ken Clarke, who, while not involved in the Department of Health or the Home Office at this time, still knew a great deal about what was going on at the heart of government. He maintains that it was the Labour government who initiated the DSPD programme and that the earlier Conservative (John Major) government of 1992-7 had no part in this.

Yet it could be argued that this is not entirely true. Throughout the 1990s, in the context of psychiatric deinstitutionalisation, there had been concern in the UK about the number of homicides carried out by people with severe mental health problems. The frequency of such homicides was alleged to be increasing but analysis of official data showed the opposite; homicides had been reducing at the rate of 3 per cent per annum over many years. ${ }^{3}$ It is not the purpose of this chapter to examine why the misleading impression was created but a considerable amount of responsibility can be placed on the publishers of tabloid newspapers who reported almost every homicide on three separate occasions: the time of the offence, the time of detention and a full and garish report of the trial. Because of the gap between each of these reports, the average reader would think that homicides were three times more frequent than they actually were.

Yet there had long been concern over the provision of services for mentally disordered offenders, and even Taylor and Gunn conceded: 'There appears to be some case for specially focused improvement of services for people with a personality disorder and/or substance misuse. $^{4}$

The Conservative government of $1992-7$, in the last throes of its chequered existence, felt it had to do something to address the widely perceived notion that highly dangerous people were milling around the countryside looking for victims. They were in the same position as Mrs Ramsbottom, who, in the Stanley Holloway sketch, ${ }^{5}$ following the unexpected departure of her son Albert into the stomach of a lion, protested: 'Someone's got to be summoned! So that was decided upon.' This is not meant to be flippant. If there were going to be high-profile cases, the government needed to be able to point to action being taken.

The first summons came in the form of the Crime (Sentences) Act of 1997, introduced by the Conservative government but enacted by the Labour one. This introduced a new power for the courts, allowing them to attach a 'Hospital Direction' to a prison sentence. A new section was added to the 1983 Mental Health Act (45A) that allowed a prisoner to be moved to hospital from prison provided 
(a) The patient is suffering from psychopathic disorder,

(b) The mental disorder (i.e. psychopathy) is of a nature or degree which makes it appropriate for the offender to be detained in a hospital, and

(c) Such treatment is likely to alleviate or prevent deterioration of the offender's condition. The new Labour government passed this Act in 1997, but it is important to note there has always been a provision for prisoners to be transferred to hospital (currently sections 47-48). Section 45a was a hybrid order that authorised the court to send a sentenced prisoner directly to hospital and then on to prison if they became medically fit before the end of their sentence. The implication of a transfer to hospital was that treatment could be provided for the individual if the doctors agreed. This became 'the treatability clause dispute'. Put simply, the government's view was 'if a mental disorder exists and is treatable, why should this decision be left to psychiatric whim?'

\section{Why the Treatability Clause Led Everyone Astray}

When the Mental Health Act was passed in 1959 'severe personality disorder' was in nobody's mind but 'psychopathic personality' was prominent, mainly because of the influence of the Scottish psychiatrist and sometime president of the Royal College of Physicians (Edinburgh), David Henderson, who had done so much to bring it to public attention in his book Psychopathic States, published in $1939 .{ }^{6}$ As it had such a powerful effect after twenty years, it influenced the wording of the Act, defining psychopathic personality as 'a persistent disorder or disability of mind (whether or not including sub-normality of intelligence) which results in abnormally aggressive or seriously irresponsible conduct on the part of the patient, and requires or is susceptible to medical treatment'. (It is important to note that this only referred to one of the three types of psychopathic personality that Henderson described: predominately aggressive; predominantly inadequate or passive; and predominantly creative.)

The problem was that this definition was, in the wording of its last clause, unworkable. It left unanswered a host of questions:

- Do all psychopathic personalities require medical treatment?

- Is psychopathic personality per se treatable?

- Do psychopathic personalities that are susceptible to treatment automatically require it (the ambiguous 'or' in the last clause suggests this is optional)?

- What does the Act suggest for those with psychopathic personality who are not susceptible to medical treatment?

It is this last question that led to much animosity. The argument came down to the level of psychiatric responsibility required for people with this disorder when not susceptible to treatment.

In 1998, Jack Straw, then Home Secretary, said on the BBC:

Twenty years ago psychiatrists were adopting what I would say what was a common sense approach to serious and dangerous persistent offenders. These days they have gone for a much narrower interpretation of the law. Quite extraordinarily for the medical profession, they have said they will only take on those patients they may regard as treatable. If that philosophy applied anywhere else in medicine there will be no progress whatsoever. It's time, frankly, that the psychiatric profession seriously examine their own practices and trying to organise them in a way that they have so far failed to do. ${ }^{7}$ 
Robert Kendell, then president of the Royal College of Psychiatrists, and well known for his plain speaking, responded robustly, if not entirely wisely under the circumstances:

'We are not very pleased with him, but even more important we are appalled by his ignorance. The Home Secretary cannot expect psychiatrists to do his dirty work for him. ${ }^{8}$

Yet Robert Kendell had an important point to make. Are all diagnosed patients required to be treatable and under care? One does not say to a palliative care physician looking after incurable patients, 'you are a physician, you have to treat these patients, you cannot just allow them to die, jump to it'. This broad generalisation also assumed that the responsibility for dealing with dangerous offenders lay mainly, if not entirely, with the medical profession.

\section{The Joint Policy of the Department of Health and the Home Office}

The focus on psychiatrists' practice only was soon realised to be a mistake and a joint approach was then suggested:

It is not just a problem for The Home Office but a problem for the Department of Health, for the prison service, for mental health services, and somehow or other we have to find a solution to that problem. The truth is we can only do that together. ${ }^{9}$

It was far from clear, however, who would lead on this. Someone had to take the initiative. It was Jack Straw at the Home Office, who recalls:

During my first eighteen months as Home Secretary I had seen a number of cases where obviously dangerous individuals were having to be released back into the community, notwithstanding the patent risk they posed, and the near certainty that they would commit further serious violence, because they had reached the end of their prison sentences, and could not be detained under the Mental Health Acts because their condition was not diagnosed as 'treatable'. ${ }^{10}$

Jack Straw also denied that the policy came from advisors as Ken Clarke has suggested (see Chapter 9):

I think you have to give the responsibility to the Labour government. The trouble is with policies like this is that you now have this semi-presidential system where everyone listens to advisers and so when public opinion gets sufficiently animated new policies are introduced without ever having been thought through.

Straw firmly contradicted this:

Ken is wrong in suggesting that this policy came from advisers, or from 'President' Blair. It came from me. I would have told Tony what I was doing, (probably in writing) but I don't recall any second-guessing from No 10 . I was rather resistant to that, and in any event there was no need, as I was getting on to develop the policy.

He also underplays the influence of the health ministers in the generation of the programme:

At this stage I cannot say for certain whether I talked to Frank Dobson, but it is highly probable, as with Alan Milburn who took over from Frank in early 1999. I might too have discussed the matter with the Shadow Home Secretary. There was no reason why not. 
In this area, support from the Conservative opposition was likely to have been forthcoming.

Straw also makes it clear that public protection was most prominent in his mind in introducing the DSPD programme and it was the Michael Stone case that initiated it:

I thought (and still think) that it was irrational that whether someone really dangerous could be detained in hospital depended not on any objective analysis of the risk they posed to the public, but on the state of psychiatric understanding and diagnosis for the time being.

My recollection is that I initiated the review within government, probably prompted by concerns expressed in the Commons and in the press. I am pretty certain that the most prominent case was indeed the Michael Stone one.

\section{Why Have a DSPD Programme When You Just Need to Change the Law?}

The DSPD programme was bound to be coercive, although it is fair to add that, at its very beginning at HMP Whitemoor, the first prisoners volunteered for the programme. The normal process at this point is to change the law. I had a hint of this developing in March 1997. Ann Coffey, MP, then the Labour opposition spokesperson on health, was recommended to accompany me on my community visits in central London in March 1997. She said she wanted to see 'psychiatry in the raw'. This turned out to be rather more accurate than was envisaged. One of the patients we were visiting in Paddington was highly suspicious, banned the community nurse from seeing her and only allowed me and Ann to come into her basement flat, where the patient proceeded to take off all her clothes and run round the kitchen table saying she was a werewolf.

Afterwards Coffey and I discussed a new Mental Health Act being introduced if Labour came to power. She expressed concern about people with personality disorders not being covered by existing legislation and asked what the profession would think about this. I said I thought it would be unwise, as we already had too much coercion, and the conversation rested there. It was, however, clear as early as 1997 that there was a move towards legislation for this group. It was never enacted. Attempts were made to enshrine the DSPD programme in law but all failed. Why?

This is even odder to explain as, only a little further north in Scotland, perhaps still following the advice of their fellow Scot, David Henderson, they solved the legal matter expeditiously. As there was already a Crime and Punishment Hospital Act passed in 1997 (see above), psychiatrists could exercise discretion in regard to a 'hospital direction' (i.e. the transfer of personality disordered offenders to hospital from prison); and this was extended further by the devolved Scottish government by simply passing legislation to allow the detention of dangerous prisoners.

\section{Conflict between Psychiatrists and Government}

The government in England was in one way trying to be encouraging to the psychiatric profession by introducing the option of treatment programmes that could allow new approaches and ideas to be tested. Yet, by introducing the programme without proper consultation - in the end it was simply bulldozed - it was received very badly. Dr Dilys Jones, at the time medical director at the Special Hospitals Services Authority and clinical strategy director to the High Security Psychiatric Services Commissioning Board, was the 
main proselytiser of the advantages of the programme for both public protection and therapeutic gain, but she was in a very small minority.

The minister who bore the main brunt of the criticism was Paul Boateng, who was appointed parliamentary under secretary of state at the Department of Health in 1997 and subsequently minister of state at the Home Office and a privy councillor in 1999 . He therefore had a foot in both the Home Office and the Department of Health camps and was well placed to defend the new programme. Yet, although he could be quite charming, he had a short temper and did not take kindly to being challenged by psychiatrists.

In my discussions with John Gunn, Emeritus Professor of Psychiatry, Institute of Psychiatry, Psychology and Neuroscience at King's College London, about these events, he fed back to me the essentials of a forensic faculty meeting in Cardiff where Boateng made it clear that the programme would be going ahead and if 'you won't play ball, we'll get the psychologists to do it'. A similar response was forthcoming at a subsequent debate at the Maudsley Hospital, as by that time the prospects of retreat had disappeared. The DSPD programme would go ahead and if these 'pesky psychiatrists' would not see its advantages they could peek in from outside and later take part if they behaved more reasonably.

Straw finally announced the introduction of the DSPD programme in January 1999:

As to the future, my honourable friend the Secretary of State for Health has made it clear that alongside prison for those who are subject to serious personality disorder and to commit offences, and hospital for those who are categorisable under the Mental Health Act, we need a third approach, under which those who are suffering from severe personality disorders and pose a grave risk to the public can be kept in securer conditions as long as they continue to pose that risk.

The programme started at HMP Whitemoor and Broadmoor Hospital in 2001 and subsequently extended to HMP Frankland in County Durham. It was intended to include Rampton Hospital but this was abandoned. The initial cost was $£ 128$ million with operational costs amounting to $£ 40$ million per annum, and by 2010 it had cost $£ 480$ million. Jack Straw and Paul Boateng had their way and the treatment programme was developed and carried out almost entirely by psychologists using esoteric interventions that had no evidence base and whose outcome was not, and never will be, properly evaluated. The prison system still has a block when it comes to evaluation by randomised trials, even though we acknowledge they are difficult to carry out in secure settings. We carried out one but randomisation at times was deliberately overruled by prison staff because of 'operational requirements'. ${ }^{11}$

\section{Cost-Effectiveness}

One of the key aims of the DSPD programme at its outset was to make the intervention 'cost-effective'. This was a completely empty aim. The criminal justice system, at least at that time and almost certainly still at present, had no plans to carry out any form of economic evaluation worthy of the term, and the history of previous initiatives included only primitive measures of costs. ${ }^{12}$ (This should not be tolerated now, and any future experiments of this nature will have to include a proper economic component, preferably carried out completely independently. Criminal justice is far too expensive to ignore its economics.) 


\section{Did the DSPD Programme Identify the Really Dangerous?}

The government policy of identifying and detaining the 'really dangerous offenders' was given a further blow by a systematic review published by Alec Buchanan and Morven Leese in the Lancet in 2001, ${ }^{13}$ which concluded that 'six people would have to be detained to prevent one violent act'. So, to prevent such acts, five out of six people would be inappropriately detained. This was a serious matter for human rights.

\section{What Went Wrong?}

In the late 1990s, there were no good links between the Royal College of Psychiatrists and the governments of the day and this impaired understanding and inhibited cooperation. Nevertheless, there was a vigorous response by the College coordinated by Mike Shooter (then president) and Tony Zigmond (vice president lead on mental health law) linked to the Mental Health Alliance formed to examine implications of a new Mental Health Act. Louis Appleby, the first national director for mental health ('mental health tsar'), appointed in 2000, was also involved; but although some in government may have listened, none were moved to intervene.

Vanessa Cameron, former chief executive of the College adds:

I do think the DSPD programme harmed the College's relationship with governments. With a few exceptions the College was rather amateur in its dealings with ministers. Things got better when during Sheila Hollins' presidency a Policy Unit, which included parliamentary monitoring, was created and professional staff employed. ${ }^{14}$

It is also fair to add that the later presidents of the College, Sheila Hollins and Dinesh Bhugra, were more mellifluous than Robert Kendell.

I personally think if there had been a minister of mental health at the time of the DSPD initiative matters might have turned out very differently. I think it very unlikely that such a programme could be introduced again without agreement with the key professionals who should have been intimately involved from the start. When one reflects on battles between governments and the doctors, there are virtually none in which the government has ultimately won. Ken Clarke managed to introduce the internal market to the NHS (see also Chapter 9) and did not give in to the British Medical Association (BMA) over pay, but he suffered greatly in his political standing in the process and probably scuppered his chances of becoming prime minister. The doctors then recovered their earning potential in 2004. In the DSPD programme debate, the doctors won in the end in that the programme was abandoned in favour of a much more modest offender pathway based in prisons. There is still room for compromise here, and how we combine public protection with psychiatric care effectively and humanely remains on the agenda. Until then, the statement by David Henderson at the beginning of this chapter remains just as true today as it was seventy years ago.

\section{Conclusion}

It would be wrong to say that the DSPD programme was a complete failure. It was a ridiculously premature experiment but it certainly improved engagement with prisoners, led to a serious review of the therapeutic environments of long-term offenders, which is described comprehensibly and well by Akerman and colleagues, ${ }^{15}$ and focused attention on 
a very neglected group, if not always for the best reasons. It also helped to stress the importance of severity in the study of personality disorder, to the degree that a single dimension of severity constitutes the new classification of personality disorder. ${ }^{16}$

Through dint of careful planning and subtle manoeuvring, in which Alison Hooper (an unsung heroine from the civil service) played a very important part behind the scenes, funding was made available for the development of personality disorder services across England, and these now cover most of the country. ${ }^{17}$ These developments still only provide a skeletal service in most areas, and many clamour for more, but I doubt whether they would have existed at all but for the DSPD programme. Perhaps if the acronym is regarded in the future as the Development of Services for Personality Disorder it will have achieved its best legacy.

\section{Key Summary Points}

- Throughout the 1990s, there had been concern in the UK about the number of homicides carried out by people with severe mental health problems. The frequency of homicides was alleged to be increasing but analysis of official data showed the opposite; homicides had been reducing at the rate of 3 per cent per annum over many years.

- The Dangerous and Severe Personality Disorder (DSPD) legislation and richly funded 'treatment' programme were introduced in the late 1990s by the then Labour government and aimed at the use of contrived psychiatric 'diagnosis' and 'treatment' to enhance public protection. The exact origin of the concept of DSPD programme remains an enigma but Jack Straw, secretary of state for the Home Office, and his Department played the leading role.

- The programme started at HMP Whitemoor and Broadmoor Hospital in 2001 and subsequently extended to HMP Frankland in County Durham. The initial cost was $£ 128$ million with operational costs amounting to $£ 40$ million per annum, and by 2010 it had cost $£ 480$ million in total.

- The legislation and 'treatment' programme were vigorously opposed by the Mental Health Alliance. The government policy of identifying and detaining the 'really dangerous offenders' was given a blow by a systematic review that concluded that, to prevent one significant violent act, five out of six people would have to be inappropriately detained.

\section{Acknowledgements}

The preparation of this chapter was a more complex assignment than first envisaged. I am particularly grateful to the politicians Jack Straw, Ken Clarke and Ann Coffey for their time and input and to Alastair Campbell for assisting in contacts. Max Rutherford's publication Blurring the Boundaries is a very balanced account of the history and context of the DSPD development and I have quoted extensively from this work. John Gunn, Tony Zigmond and Vanessa Cameron contributed valuable additions and corrections to the original draft, and the editors of his book have done so also, with aplomb. I am also thankful to my many colleagues who were involved in our own evaluation of the DSPD programme and gave me additional insights, particularly Deborah Rutter, Conor Duggan, Rick Howard, Barbara Barrett, Eddie Kane and Helen Tyrer. I have also had additional comments from colleagues 
in the prison service, who wish to remain anonymous, who inform me that the DSPD therapeutic programme is still active; the programme has not gone away.

\section{Notes}

1. D. K. Henderson, Psychopathic states. British Journal of Delinquency (1951) 2: 84-7.

2. P. Tyrer, S. Cooper, D. Rutter et al., The assessment of dangerous and severe personality disorder: Lessons from a randomised controlled trial linked to qualitative analysis. Forensic Psychology and Psychiatry (2009) 20: 132-46; P. Tyrer, C. Duggan, S. Cooper et al., The successes and failures of the DSPD experiment: The assessment and management of severe personality disorder. Medicine, Science and the Law (2010) 50: 95-9; P. Tyrer, R. Mulder, Y.-R. Kim and M. J. Crawford, The development of the ICD-11 classification of personality disorders: An amalgam of science, pragmatism and politics. Annual Review of Clinical Psychology (2019) 15: 481-502.

3. P. J. Taylor and J. Gunn, Homicides by people with mental illness: Myth and reality. British Journal of Psychiatry (1999) 174: 9-14.

4. Ibid.

5. M. Edgar, The Lion and Albert (Stanley Holloway Monologues). London: Francis, Day \& Hunter, 1934.

6. D. K. Henderson, Psychopathic States. New York: WW Norton, 1939.

7. Jack Straw quoted in M. Rutherford, Blurring the Boundaries. London: Sainsbury Centre for Mental Health: 2010.

8. BBC News, Psychiatrists accuse Straw of ignorance. BBC News, 26 October 1998.

9. Alan Milburn, House of Commons Select Committee on Health, 2000, quoted in Rutherford, Blurring the Boundaries.

10. Jack Straw is quoted here and in what follows from personal communication between him and the author.

11. Tyrer, Cooper, Rutter et al., The assessment of dangerous and severe personality disorder.

12. B. Barrett, S. Byford, H. Seivewright, S. Cooper, C. Duggan and P. Tyrer, The assessment of dangerous and severe personality disorder: Service use, cost and consequences. Forensic Psychology and Psychiatry (2009) 20: $120-31$.

13. A. Buchanan and M. Leese, Detention of people with dangerous severe personality disorders: A systematic review. Lancet (2001) 358: 1955-9.

14. Personal communication.

15. G. Akerman, A. Needs and C. Bainbridge, eds, Transforming Environments and Rehabilitation: A Guide for Practitioners in Forensic Settings and Criminal Justice. Abingdon: Routledge, 2018.

16. Tyrer, Mulder, Kim and Crawford, The development of the ICD-11 classification of personality disorders.

17. O. Dale, F. Sethi, C. Stanton et al., Personality disorder services in England: Findings from a national survey. BJPsych Bulletin (2017) 41: 147-53. 